\title{
Quantitative in vivo measurement of early axonal transport deficits in a triple transgenic mouse model of Alzheimer's disease using manganese-enhanced MRI
}

\author{
Jieun Kim ${ }^{a}$, In-Young Choia,b,c, Mary L. Michaelis ${ }^{d}$, and Phil Lee ${ }^{a, c,{ }^{*}}$ \\ aHoglund Brain Imaging Center, University of Kansas Medical Center, Kansas City, KS 66160, \\ USA \\ bDepartment of Neurology, University of Kansas Medical Center, Kansas City, KS 66160, USA \\ 'Department of Molecular and Integrative Physiology, University of Kansas Medical Center, \\ Kansas City, KS 66160, USA \\ dDepartment of Pharmacology and Toxicology, University of Kansas, Lawrence, KS 66045, USA
}

\section{Abstract}

Impaired axonal transport has been linked to the pathogenic processes of Alzheimer's disease (AD) in which axonal swelling and degeneration are prevalent. The development of non-invasive neuroimaging methods to quantitatively assess in vivo axonal transport deficits would be enormously valuable to visualize early, yet subtle, changes in the AD brain, to monitor the disease progression and to quantify the effect of drug intervention. A triple transgenic mouse model of $\mathrm{AD}$ closely resembles human AD neuropathology. In this study, we investigated age-dependent alterations in the axonal transport rate in a longitudinal assessment of the triple transgenic mouse olfactory system, using fast multi-sliced $\mathrm{T}_{1}$ mapping with manganese-enhanced MRI. The data show that impairment in axonal transport is a very early event in AD pathology in these mice, preceding both deposition of $A \beta$ plaques and formation of Tau fibrils.

\section{Keywords}

Axonal transport; Alzheimer's disease; MEMRI; triple transgenic mouse model; $\mathrm{T}_{1}$ mapping

\section{Introduction}

Neuronal cell function and viability critically depend on effective and timely axonal transport (AT), i.e. the process in which intracellular cargoes including neurotransmitters, proteins and organelles are trafficked through axons to the nerve terminals. Axonal transport deficits have been implicated in neurodegenerative diseases such as Alzheimer's disease (AD) (Morfini et al. 2009; Wilson 2008). Two major pathological hallmarks of AD, accumulation of $\beta$-amyloid $(A \beta)$ deposition in plaques and fibrillization of Tau, appear to

(C) 2010 Elsevier Inc. All rights reserved

"Corresponding Author: Phil Lee, Ph.D., Hoglund Brain Imaging Center, 3901 Rainbow Blvd, Mail Stop 1052, University of Kansas Medical Center, Kansas City, KS 66160, USA, Tel: 913588 0454, Fax: 913588 9071, plee2@kumc.edu.

Note: Please note the corresponding author's legal name change from Sang-Pil Lee to Phil Lee.

Publisher's Disclaimer: This is a PDF file of an unedited manuscript that has been accepted for publication. As a service to our customers we are providing this early version of the manuscript. The manuscript will undergo copyediting, typesetting, and review of the resulting proof before it is published in its final citable form. Please note that during the production process errors may be discovered which could affect the content, and all legal disclaimers that apply to the journal pertain. 
cause axonopathy. Tau is a microtubule-associated protein that stabilizes and is essential for maintaining normal axonal transport processes (Gotz et al. 2006). The dysregulation of axonal transport leads to synaptic dysfunction and synaptic/neuronal loss in animal models of $\mathrm{AD}$. The presence of axonopathy in human $\mathrm{AD}$ has been supported by findings of axonal swelling, accumulated mitochondrial components in lysosomes, accumulation of vesicles in cell bodies, and dysfunctional synaptic vesicles at nerve terminals (Gotz et al. 2006; Stokin et al. 2005).

Increased axonopathy has been reported in animal models of amyloidosis including the Tg2576 mouse that over-expresses a mutant human amyloid precursor protein (APP) and an APP mutant mouse that also that also expresses a human presenilin mutation (PS1) (Smith et al. 2007; Wirths et al. 2007). It has been suggested that the axonal transport deficits are occurring in conjunction with the accumulation of insoluble $A \beta$ and prior to $A \beta$ plaque formation in the $\mathrm{Tg} 2576 \mathrm{AD}$ mouse model. Many of the transgenic AD mouse models exhibit axonal swelling that likely interferes with normal axonal transport of essential cellular components, mitochondria, and other vesicles. Mutations in the Tau gene also seriously disrupt microtubule function and lead to dystrophic axonal processes (Hutton et al. 1998; Spillantini et al. 1998). However, the mechanisms by which both aging and various genetic insults disrupt axonal transport have not been clearly delineated (De Vos et al. 2008; Morfini et al. 2009; Schindowski et al. 2007). Therefore, understanding the role of A $\beta$ and Tau in the development of axonal transport deficits in AD brain is crucial for developing new strategies in early diagnosis and possible treatments to slow progression of AD pathology.

Axonal transport rates have conventionally been measured in vitro using radiotracers or fluorescent dyes in excised neurons. These conventional methods are invasive and cannot be used in vivo. Recently in vivo approaches to measuring axonal transport rates have been reported using magnetic resonance imaging (MRI) methods. One commonly used form of MRI, manganese-enhanced magnetic resonance imaging (MEMRI), involves application of manganese chloride $\left(\mathrm{MnCl}_{2}\right)$ as a contrast agent to follow axonal transport. MEMRI measures the shortening of the longitudinal relaxation rate constant $\left(R_{1}=1 / T_{1}\right)$ over time after administering an $\mathrm{MnCl}_{2}$ solution (Chuang et al. 2006; Kim et al. 2009). Manganese ion $\left(\mathrm{Mn}^{2+}\right)$ is a paramagnetic, calcium analogue that has been used as a contrast agent in MRI. It is a trans-synaptic tracer that is taken up into neurons via voltage-gated calcium channels, packaged into vesicles, and transported down the axon in a microtubule-dependent manner. After being released from pre-synaptic terminals, $\mathrm{Mn}^{2+}$ crosses the synapse, enters postsynaptic neurons, and is distributed through interconnecting brain areas by selective anterograde transport. In a series of papers, Pautler and co-workers established MEMRI as a viable neuronal tract tracing method that allows for the measurement of axonal transport rates (Pautler et al. 1998; Pautler et al. 2002; Pautler 2004). Given that aging is the major risk factor for $\mathrm{AD}$, it is worth noting that axonal transport rates in the CNS of rats, measured using MEMRI, decrease with normal aging (Cross et al. 2008).

Currently, most MEMRI studies rely on $\mathrm{T}_{1} \mathrm{w}$ MEMRI methods to detect changes in signal enhancement from $\mathrm{Mn}^{2+}$ accumulation (Serrano et al. 2008; Smith et al. 2007). However, MRI contrast in $\mathrm{T}_{1} \mathrm{w}$ MEMRI methods can only be useful for a narrow range of $\mathrm{Mn}^{2+}$ concentration in the target tissue. In addition, quantification of $\mathrm{T}_{1} \mathrm{w}$ MEMRI is not reliable for multi-session or longitudinal studies due to variations in the signal intensity by other contributing factors such as flip angle and base line $\mathrm{T}_{1}$ values. Unlike $\mathrm{T}_{1} \mathrm{w}$ MEMRI, the parametric $\mathrm{T}_{1}$ mapping method provides reliable quantification as the signal sensitivity does not depend on the $\mathrm{Mn}^{2+}$ concentration. The $\mathrm{T}_{1}$ mapping method also allows the $\mathrm{Mn}^{2+}$ contrast comparison in multiple sessions because this method does not require a normalization process. In this study, we have used our previously-developed fast multi-slice 
Look-Locker sequence with multiple phase encodings per inversion pulse, which enabled $\mathrm{T}_{1}$ mapping in short acquisition time (Lee 2007).

The olfactory system is particularly favorable for the study of axonal transport since $\mathrm{Mn}^{2+}$ can be delivered noninvasively. The delivery of $\mathrm{Mn}^{2+}$ into mouse olfactory epithelium can easily be achieved via injection of $\mathrm{MnCl}_{2}$ solution through the nasal pathway as it connects primary neurons in the epithelium to cortical projections without necessitating transport of tracers across the blood-brain barrier (Cross et al. 2004; Cross et al. 2008). Successful measurement of an axonal transport deficit has been achieved in the olfactory system of an APP transgenic mouse model of AD using the MEMRI technique (Smith et al. 2007; Wirths et al. 2007).

In this study, we have used an animal model of $\mathrm{AD}$ that expresses both $\mathrm{A} \beta$ and Tau pathology, a triple transgenic mouse model of AD (3xTg-AD). The 3xTg-AD is a widely used as an animal model for human $\mathrm{AD}$ because it expresses mutations in $\mathrm{PS} 1_{\mathrm{M} 146 \mathrm{~V}}$, $\mathrm{APP}_{\text {Swe }}$, and Tau $\mathrm{P}_{301 \mathrm{~L}}$, leading to both $\mathrm{A} \beta$ and Tau pathology (Oddo et al. 2003). The $3 \times T g-A D$ mice develop $A \beta$ and Tau pathologic lesions in a sequential manner. By measuring axonal transport deficits in this mouse model at different ages, we investigated the effects of the combination of $A \beta$ and Tau aggregates on axonal transport at an early stage of the disease development in these mice. We hypothesize that occurrence of early axonal transport deficits is likely due to intraneuronal $A \beta$ first, followed by Tau hyperphosphorylation and fibrillization, leading to progressive axonal transport deficits. Using quantitative $T_{1}$ mapping rather than qualitative $T_{1} \mathrm{w}$ imaging together with non-invasive MEMRI, we demonstrate that these methods can be reliably employed to detect agedependent axonal transport impairments.

\section{Materials and Methods}

\section{Animals}

All the animals were handled in compliance with institutional and national regulations and policies. The protocols were approved by the Institutional Animal Care and Use Committee. $3 x T g-A D$ mice were obtained from the mouse colony established at the University of Kansas from a breeding pair obtained from Dr. Laferla at the University of California at Irvine. 3xTg-AD mice harbor $\mathrm{PS}_{\mathrm{M} 146 \mathrm{~V}}$, $\mathrm{APP}_{\mathrm{Swe}}$, and $\mathrm{Tau}_{\mathrm{P} 301 \mathrm{~L}}$ and progressively develop both $A \beta$ plaques and NFT pathology with accompanying neuronal death in brain regions similar to those seen in human AD. These animals develop intracellular A $\beta$ pathology in neocortex at 3 months of age, extracellular $A \beta$ pathology in frontal cortex at 6 months, and Tau pathology at 12 months. The presence of both Tau and APP transgenes in olfactory bulb (OB) has been confirmed by Western blotting (Oddo et al. 2003).

Three age groups of $3 \times \mathrm{Tg}-\mathrm{AD}$ mice and age-matched wt mice were studied: 2 months (2 mos), $\mathrm{n}=9$ for wt and $\mathrm{n}=8$ for $3 \mathrm{xTg}-\mathrm{AD} ; 3$ months $(3$ mos), $\mathrm{n}=8$ for wt and $\mathrm{n}=4$ for $3 \mathrm{xTg}$ $\mathrm{AD} ; 15$ months ( 15 mos) of age, $\mathrm{n}=5$ for wt and $\mathrm{n}=6$ for $3 \mathrm{xTg}$-AD.

\section{Manganese $\left(\mathrm{Mn}^{2+}\right)$ Administration}

Animals were anesthetized with $4 \%$ isoflurane mixed in $4 \mathrm{~L} / \mathrm{min}$ air and $1 \mathrm{~L} / \mathrm{min} \mathrm{O}_{2}$ for 5 min. Manganese chloride $\left(\mathrm{MnCl}_{2}\right)$ solution was administered intranasally. A nasal lavage of $4 \mu \mathrm{L}$ of isotonic $\mathrm{MnCl}_{2}$ solution (160 mM) (Sigma-Aldrich, St. Louis, MO) was administered to the left nostril using a Hamilton syringe (Hamilton Company, Reno, NV). Animals were then returned to a fresh cage on a heating pad, stimulated using amyl acetate for 15 min to enhance uptake of $\mathrm{Mn}^{2+}$ in the olfactory neurons, and allowed to recover fully before MRI sessions. We chose unilateral administration of $\mathrm{MnCl}_{2}$ solution to reduce the dosage of the $\mathrm{MnCl}_{2}$ solution to limit possible toxicity and to facilitate confirmation of the 
successful administration of $\mathrm{MnCl}_{2}$ by comparing signal enhancements in the ipsilateral and contralateral turbinate.

\section{Magnetic resonance imaging}

All MR studies were performed using a 9.4 T Varian INOVA system (Varian Inc., CA), equipped with a $12 \mathrm{~cm}$ gradient coil $(40 \mathrm{G} / \mathrm{cm}, 250 \mu \mathrm{s})$. A $6 \mathrm{~cm}$ diameter Helmholtz volume transmit coil and a $7 \mathrm{~mm}$ diameter surface receive coil with de-tune capability were used for MR imaging. Animals were anesthetized and maintained with $1-1.5 \%$ isoflurane during MRI sessions. Mice were under anesthesia for less than $40 \mathrm{~min}$ for each MRI session. Core body temperature was maintained at $37{ }^{\circ} \mathrm{C}$ using a circulating hot water pad and a temperature controller (Cole-Palmer, NY). Respiration was monitored via a pressure pad under the animal (SA Instruments, NY). MR data were acquired before and $1 \mathrm{~h}, 6 \mathrm{~h}$, and $24 \mathrm{~h}$ after unilateral and intranasal administration of $\mathrm{MnCl}_{2}$ solution in four separate MRI sessions. These four MRI time points were chosen based on the time course of the $\mathrm{R}_{1}$ changes in the olfactory bulb (OB) and lateral olfactory tracts (LOT) after intranasal $\mathrm{MnCl}_{2}$ administration (data not shown). The data showed that $\mathrm{R}_{1}$ in the $\mathrm{OB}$ changed linearly with time from $1 \mathrm{~h}$ to up to $6 \mathrm{~h}$ post $\mathrm{MnCl}_{2}$ administration. Therefore, $1 \mathrm{~h}$ and $6 \mathrm{~h}$ time points were chosen to calculate axonal transport rates, to remove the effect of the initial transport delay from the turbinate to the $\mathrm{OB}$, and to achieve high detectability $\mathrm{R}_{1}$ changes in $\mathrm{OB}$ by allowing enough time for transported $\mathrm{Mn}^{2+}$ to accumulate in the $\mathrm{OB}$. The $24 \mathrm{~h}$ time point was chosen to provide enough time for axonal transport of $\mathrm{Mn}^{2+}$ to the more distal LOT.

$\mathrm{T}_{1}$ maps were measured using a non echo planar imaging based, multi-slice $\mathrm{T}_{1}$ sequence modified from the Look-Locker sequence (Look et al. 1970) to acquire two phase encodings per inversion pulse $(\mathrm{TR} / \mathrm{TE}=4 / 2 \mathrm{~ms}, \mathrm{FOV}=2 \mathrm{~cm}$, matrix $=128 \times 128$, thickness $=0.5 \mathrm{~mm}$, flip angle $=20^{\circ}, 22$ inversion times from $40-5470 \mathrm{~ms}$, and acquisition time $\left.=8.5 \mathrm{~min}\right) . \mathrm{B}_{1}$ maps were measured to correct the effect of flip angle variations on $\mathrm{T}_{1}$ maps $(\mathrm{TR} / \mathrm{TE}=$ $200 / 3.7 \mathrm{~ms}$, matrix $=128 \times 128, \mathrm{NEX}=4$, thickness $=0.5 \mathrm{~mm})($ Pan et al. 1998). High resolution $\mathrm{T}_{1}$-weighted $\left(\mathrm{T}_{1} \mathrm{w}\right)$ spin-echo images were also acquired to visualize turbinate areas of the olfactory system $(\mathrm{TR} / \mathrm{TE}=600 / 10 \mathrm{~ms}, \mathrm{NEX}=2$, matrix $=256 \times 256$, thickness $=0.45 \mathrm{~mm}$, scan time $=5 \mathrm{~min})$.

\section{MEMRI Data Analysis}

The $T_{1}$ and $B_{1}$ values of each pixel were calculated using a program written in IDL (RSI, $\mathrm{CO})$. The $\mathrm{R}_{1}$ values were calculated based on the following equation:

$$
R_{1}=\frac{1}{T_{1}}=\frac{1}{T_{1}^{*}}+\frac{(\ln (\cos \theta)}{\tau}
$$

where $\mathrm{T}_{1} *$ is the apparent $\mathrm{T}_{1}$ obtained from the fitting of inversion recovery signal intensities using the Levenberg-Marquardt algorithm, $\tau$ is the duration between successive excitations of the same slice, and $\theta$ is flip angle. Ideally, if the exact flip angle at each pixel is known, the $\mathrm{T}_{1}$ can be computed from Eq. (1) after obtaining $\mathrm{T}_{1} *$ without further information. However, the $\mathrm{B}_{1}$ field inhomogeneity from the imperfect excitation pulse and the RF coil profile causes the flip angle to differ from the intended value. Therefore, $B_{1}$ field maps were used to obtain the actual flip angle value, $\theta$ in Eq. (1) in a pixel-by-pixel basis. Region of interest (ROI) analysis was performed using STIMULATE software (Strupp 1996). Axonal transport rate index (ATRI) of olfactory sensory neurons was calculated from the $\mathrm{R}_{1}$ changes in an ROI of olfactory bulb between $1 \mathrm{~h}$ and $6 \mathrm{~h}$ after $\mathrm{MnCl}_{2}$ administration $\left(\left(\mathrm{R}_{1(6 \mathrm{~h})}-\mathrm{R}_{1(1 \mathrm{~h})}\right) / 5\right)$. ATRI at the LOT was estimated from the time course of $\mathrm{R}_{1}$ changes in an ROI of the LOT between pre and post $24 \mathrm{~h} \mathrm{MnCl}_{2}$ administration $\left(\left(\mathrm{R}_{1(24 \mathrm{~h})}-\mathrm{R}_{1(\mathrm{pre})}\right) / 24\right)$. 
$\mathrm{Mn}^{2+}$ uptake in the turbinate was compared between wt and 3xTg-AD mice at $1 \mathrm{~h}$ post $\mathrm{MnCl}_{2}$ administration. The MR signal intensity in the spin-echo $\mathrm{T}_{1} \mathrm{w}$ images was measured from both enhanced (left, L) and non-enhanced (right, R) sides of the turbinate. Unlike gradient-echo based $T_{1}$ mapping methods, spin-echo $T_{1}$ w MEMRI does not suffer from the macroscopic susceptibility induced signal loss where the susceptibility effect is pronounced due to the air and tissue interface, such as the turbinate regions. The MR signal intensity ratio between two sides at $1 \mathrm{~h}$ post $\mathrm{MnCl}_{2}$ administration provided an index for $\mathrm{Mn}^{2+}$ uptake.

Trans-synaptic transmission efficiency index of $\mathrm{Mn}^{2+}$ was estimated from the ATRI at the $\mathrm{OB}$ and LOT. Since the concentration of $\mathrm{Mn}^{2+}$ at LOT is proportional to the concentration in the $\mathrm{OB}$ and the efficiency of synaptic transmission from the olfactory sensory neurons to mitral cells in the OB glomeruli, the trans-synaptic transmission efficiency index was calculated by the ratio of the ATRIs at LOT and OB.

Two-tailed Student t-tests were performed to compare group means of ATRIs using Microsoft Excel. All data are presented as mean \pm SD. A P-value of less than 0.05 was considered statistically significant.

\section{Results}

\section{High resolution MEMRI of the $3 \times \mathrm{Tg}-\mathrm{AD}$ mouse brain}

The coronal $\mathrm{Mn}^{2+}$ enhanced $\mathrm{T}_{1} \mathrm{w}$ MR image ( $\mathrm{T}_{1} \mathrm{w}$ MEMRI) clearly shows structures and layers of the nasal and olfactory system of the $3 \times \mathrm{Tg}$-AD mouse (Fig. 1A Top). The $\mathrm{T}_{1} \mathrm{w}$ MEMRI was acquired at $6 \mathrm{~h}$ post $\mathrm{MnCl}_{2}$ administration in a 5 min data acquisition time and demonstrates the $\mathrm{Mn}^{2+}$ accumulation from the turbinate to the OB. Three major areas (i: turbinate; ii: OB; iii: LOT in Fig. 1A (Top: coronal MRI, Bottom: sagittal MRI)) were chosen to calculate axonal transport rates from the turbinate to the $\mathrm{OB}$, and from the turbinate to the LOT. The first slice position (i in Fig. 1A) was placed where olfactory sensory neurons are located in the olfactory epithelium of the turbinate. The second slice position (ii) was placed where olfactory neurons project to glomeruli in the olfactory bulbs. The third slice position (iii) was placed where olfactory output neurons (mitral cells) are receiving inputs from glomeruli and projecting to various targets in the brain via olfactory tracts. $\mathrm{Mn}^{2+}$ accumulates following the olfactory neural circuits from olfactory sensory neurons to olfactory tracts, and MEMRI were measured at $1 \mathrm{~h}, 6 \mathrm{~h}$, and $24 \mathrm{~h}$ post $\mathrm{MnCl}_{2}$ administration through the left nasal cavity.

\section{$\mathrm{Mn}^{2+}$ uptake in the turbinate at $1 \mathrm{~h}$ post $\mathrm{MnCl}_{2}$ administration}

High resolution $\mathrm{T}_{1} \mathrm{w}$ MEMRI of the turbinate (Fig. $1 \mathrm{~B}(\mathrm{i})$ ) was acquired at $1 \mathrm{~h}$ post $\mathrm{MnCl}_{2}$ administration. Unilateral MR signal enhancement in the left turbinate (marked by red arrow) shows the structure in detail, including nasal cavities. The signal enhancement in the turbinate indicates $\mathrm{Mn}^{2+}$ uptake into the olfactory sensory neurons during the initial hour. There was no difference in signal enhancement between wt and 3xTg-AD mice in any age, 2 mos, 15 mos or 18 mos of age ( $p=0.57, n=5$ for wt and $n=6$ for $3 \times T g-A D)$.

\section{$\mathrm{Mn}^{2+}$ transport in the $\mathrm{OB}$ at $6 \mathrm{~h}$ post $\mathrm{MnCl}_{2}$ administration}

At $6 \mathrm{~h}$ post $\mathrm{MnCl}_{2}$ administration, the layered structure of the $\mathrm{OB}$ was clearly identifiable with MR signal enhancement through $\mathrm{Mn}^{2+}$ accumulation in the glomerular layer (GL) and the mitral cell layer (MCL) in the high resolution $\mathrm{T}_{1} \mathrm{w}$ MEMRI (Fig. 1B(ii)) with the expanded view of the figure in the left panel of Fig. 1C. The external plexiform (EPL) and granule cell (GrO) layers did not show clear signal enhancement. Cellular layers of the OB in mice are detailed in a histological section figure (Fig. 1C, www.wikipedia.org) to illustrate the matching structure in the $\mathrm{T}_{1} \mathrm{w}$ MEMRI. 


\section{Quantitative measurement of axonal transport rate using $T_{1}$-mapping}

Figure 2 shows representative $\mathrm{T}_{1}$ maps (upper row, pseudo color) and $\mathrm{T}_{1} \mathrm{w}$ images (lower row, gray color) of the OB of 3 mos old wt (Fig. 2A) and 3xTg-AD (Fig. 2B) mice at baseline, and $1 \mathrm{~h}, 6 \mathrm{~h}$, and $24 \mathrm{~h}$ post $\mathrm{MnCl}_{2}$ administration through the nasal cavity. At $1 \mathrm{~h}$ post $\mathrm{MnCl}_{2}$ administration, a slight $\mathrm{T}_{1}$ reduction was observed in the medial and lateral regions of the left $\mathrm{OB}$ in the $\mathrm{T}_{1}$ map of wt. The corresponding $\mathrm{T}_{1} \mathrm{w}$ signal enhancement was also observed in the $\mathrm{T}_{1} \mathrm{w}$ image of wt. No discernable changes were detectable in either the $\mathrm{T}_{1}$ maps or $\mathrm{T}_{1} \mathrm{w}$ MRI of $3 \mathrm{xTg}-\mathrm{AD}$ mice. At $6 \mathrm{~h}$ and $24 \mathrm{~h}$, both wt and $3 \mathrm{xTg}$-AD mice showed clear $\mathrm{T}_{1}$ reductions ( $\mathrm{T}_{1} \mathrm{w}$ MEMRI signal enhancement) at the medial, lateral and dorsal parts of the left $\mathrm{OB}$. The time course of $\mathrm{R}_{1}$ was calculated from the ROI placed mostly in the glomerular layer of the lateral part of the OB (Square in Fig. 2A, top row). Group comparisons of $\mathrm{R}_{1}$ in the $\mathrm{OB}$ of 3 mos old mice between wt and 3xTg-AD mice are shown in Fig. 4C. $R_{1}$ values of 3xTg-AD mice were significantly lower at $1 \mathrm{~h}$ (wt: $0.82 \pm 0.12 \mathrm{~s}^{-1}$, 3xTg-AD: $0.69 \pm 0.04 \mathrm{~s}^{-1} ; \mathrm{p}=0.043$ ), $6 \mathrm{~h}\left(\mathrm{wt}: 1.84 \pm 0.27 \mathrm{~s}^{-1}, 3 \mathrm{xTg}-\mathrm{AD}: 1.31 \pm 0.0 .28 \mathrm{~s}^{-1} ; \mathrm{p}\right.$ $=0.005$ ) and 24h (wt: $\left.1.76 \pm 0.36 \mathrm{~s}^{-1}, 3 \times \mathrm{Tg}-\mathrm{AD}: 1.25 \pm 0.24 \mathrm{~s}^{-1} ; \mathrm{p}=0.018\right)$ post $\mathrm{MnCl}_{2}$ administration, indicating lower axonal transport of $\mathrm{Mn}^{2+}$ in $3 \times \mathrm{Tg}-\mathrm{AD}$ than that in wt mice.

\section{Lower axonal transport rate in the OB of 3xTg-AD}

An average ATRI of the OB was calculated from the difference between $R_{1}$ values at $1 \mathrm{~h}$ and $6 \mathrm{~h}$ in the same manner as in Fig. 2C. Group comparisons between 3mos old 3xTg-AD and wt showed that $3 \times \mathrm{Tg}-\mathrm{AD}$ mice had a significantly lower axonal transport rate $(\mathrm{p}=0.034)$ (Fig. 3). Figure $3 \mathrm{~A}$ shows $\mathrm{T}_{1}$ maps and the corresponding $\mathrm{T}_{1} \mathrm{w}$ MEMRI of the OB (slice position ii in Fig. 1A) with the clear unilateral signal enhancement in the left $\mathrm{OB}$ of 3xTg$\mathrm{AD}$ at $6 \mathrm{~h}$ post $\mathrm{MnCl}_{2}$ administration. The axonal transport rate remained lower in $3 \times \mathrm{Tg}-\mathrm{AD}$ mice compared to wt mice at $15 \mathrm{mos}$, although it did not reach statistical significance $(\mathrm{p}=$ 0.087). The overall ATRI of $3 \times$ Tg-AD mice was lower by $27 \%$ at 3 mos and lower by $54 \%$ at 15 mos compared to wt mice.

The effect of aging on the axonal transport rate was assessed in three age groups ( 2 mos, 3 mos, and 15 mos). The average ATRI fell with age for both wt and 3xTg-AD groups although 3xTg-AD mice transport rates fell more in all age groups. The difference between young mice ( 2 mos and 3 mos) and old mice was statistically significant in both groups (3xTg-AD: $\mathrm{p}=0.001$ for 2 mos vs. 15 mos, and $\mathrm{p}=0.028$ for 3 mos vs. 15 mos; wt: $\mathrm{p}=$ 0.033 for 2 mos vs. $15 \mathrm{mos}$, and $\mathrm{p}=0.017$ for 3 mos vs. $15 \mathrm{mos}$ ). Age-dependent decreases of the ATRI from 2 mos of age were $22 \%$ and $69 \%$ at 3 mos and 15 mos of age for $3 \times \mathrm{Tg}-$ AD mice, respectively, while the decreases were $9 \%$ and $43 \%$ for wt mice.

\section{Measurement of trans-synaptic axonal transport rate in the lateral olfactory tract}

Figure $4 \mathrm{~A}$ shows $\mathrm{T}_{1}$ maps and the corresponding $\mathrm{T}_{1} \mathrm{w}$ MEMRI of the LOT (slice position iii in Fig. 1A) with the unilateral $\mathrm{T}_{1}$ reduction in the left LOT of $3 \times \mathrm{Tg}-\mathrm{AD}$ at $24 \mathrm{~h}$ post $\mathrm{MnCl}_{2}$ administration. At earlier time points ( $1 \mathrm{~h}$ or $6 \mathrm{~h}$ post $\mathrm{MnCl}_{2}$ administration), no signal enhancement was observed in the LOT.

The ATRI was measured at the LOT in 2 mos, 3 mos and 15 mos old 3xTg-AD mice. Overall the axonal transport deficits in the LOT were similar to transport deficits observed in the $\mathrm{OB}$ of 3 mos and 15 mos mice. The results of the comparison indicate that a dramatic axonal transport deficit occurred at 3 mos $(\mathrm{p}=0.039)$ of age and persisted in older age mice $(15$ mos $)(\mathrm{p}=0.028)$ compared to age-matched wt mice (Fig. 4B). The difference between young mice ( 2 mos and 3 mos) and old mice was statistically significant in $3 \times \mathrm{Tg}-\mathrm{AD}$ mice ( $p=0.003$ for 2 mos vs. 15 mos, and $p=0.016$ for 3 mos vs. $15 \mathrm{mos}$ ), but there were no differences in wt mice ( $p>0.1)$. The age-dependent decreases of the ATRI from 2 mos $3 x \mathrm{Tg} \mathrm{AD}$ mice were $14 \%$ and $54 \%$ at 3 mos and 15 mos of age, respectively. Trans-synaptic 
transmission efficiency index of $\mathrm{Mn}^{2+}$ in $3 x \mathrm{Tg}$-AD mice did not differ from that of wt mice in all age groups $(\mathrm{p}>0.19)$.

\section{Discussion}

\section{Early axonal transport deficit in the 3xTg-AD mouse brain}

In this study, axonal transport deficits in 3xTg-AD mice preceded deposition of $A \beta$ plaques and neurofibrillary tangles. Our findings of the early axonal transport deficit in 3xTg-AD mice at 3 mos of age are coincident with the timing of intraneuronal $A \beta$ accumulation, as $3 \mathrm{xTg}-\mathrm{AD}$ mice are known to develop this pathological lesion at $3-4$ mos in the neocortex, extracellular $A \beta$ pathology such as $A \beta$ plaque deposition at 5-6 mos in the frontal cortex, and the Tau pathology at 12 mos of age (Oddo et al. 2003). In light of the recent demonstration by Pigino and colleagues that intraneuronal A $\beta$, especially oligomers, can induce fast axonal transport deficits in the giant squid axoplasm (Pigino et al. 2009), the intraneuronal $\mathrm{A} \beta$ accumulation in $3 \times \mathrm{Tg}-\mathrm{AD}$ mice at $3-4$ mos of age may be a contributor to the observed axonal transport deficits. Furthermore, the axonal transport deficits could be linked to cognitive impairment observed in 3xTg-AD at the same age (Billings et al. 2005). Early axonal transport deficits in 3xTg-AD were also consistent with previous findings in $\mathrm{Tg} 2576$ mice in which axonal transport deficits occurred at $6-7$ mos of age, prior to $\mathrm{A} \beta$ plaque deposition (Smith et al. 2007).

The axonal transport deficits in $3 \mathrm{xTg}-\mathrm{AD}$ persisted to the later age of $15 \mathrm{mos}$, the age range in which both extracellular $A \beta$ and Tau pathologies are known to be present (Oddo et al. 2003). Although extracellular $A \beta$ and/or Tau pathology may not contribute to the initial axonal transport deficits, it is highly probable that both pathologies contribute to the further reduction of axonal transport rates at a later age compared to those at 3 mos of age.

\section{Trans-synaptic axonal transport of $\mathrm{Mn}^{2+}$}

The axonal transport in the LOT of 3xTg-AD mice was also impaired as observed in the OB of 3 mos and 15 mos. Note that the ATRI in the LOT is an order of magnitude lower than that in the OB. The ATRI reflects the rate of $\mathrm{Mn}^{2+}$ accumulation in each region of interest and the amount of $\mathrm{Mn}^{2+}$ accumulation at a given time in each region depends on the distance from the $\mathrm{Mn}^{2+}$ uptake site (i.e., turbinate) and the availability of $\mathrm{Mn}^{2+}$ in the neurons for transport after the uptake. The longer axonal distances from the turbinate to the LOT and the $\mathrm{Mn}^{2+}$ dilution factor at the $\mathrm{OB}$ as $\mathrm{Mn}^{2+}$ are transported from the $\mathrm{OB}$ to various brain regions have contributed to the lower accumulation of $\mathrm{Mn}^{2+}$ in the LOT.

The transport deficits at the LOT could be caused either by slow movement of vesicles along the axons or by low efficiency of synaptic transport of vesicles, since the ATRI at the olfactory tracts includes contributions from (1) axonal transport into the OB, (2) synaptic transmission from the olfactory sensory neurons to mitral cells at glomeruli in the OB and (3) axonal transport to the LOT. Considering that there was no difference in trans-synaptic transmission efficiency indices of $\mathrm{Mn}^{2+}$ (synaptic transmission from the olfactory sensory neurons to mitral cells) between $3 \times \mathrm{Tg}-\mathrm{AD}$ and wt mice in all age groups, the lower axonal transport rate index at the LOT in $3 \mathrm{xTg}-\mathrm{AD}$ is most likely due to slow axonal transport within the neurons.

\section{Quantitative measurement of $T_{1}$ mapping at high magnetic field, 9.4 T}

We have achieved quantitative axonal transport rate measurements in the mouse brain in vivo using our $\mathrm{T}_{1}$ mapping method. One of the major challenges of $\mathrm{T}_{1}$ mapping in mice is the long acquisition time when using multiple TR / flip angle sequences or conventional single-slice Look-Locker sequences. Another challenge is the possible image distortion and/ 
or signal dropout when echo planar imaging sequences are used to reduce the acquisition time. To overcome these problems, we used our fast multi-slice Look-Locker method that provided $T_{1}$ mapping in less than 9 min. By using $B_{1}$ corrected quantitative $T_{1}$ mapping, with an excellent image resolution $\left(156 \times 156 \times 500 \mu \mathrm{m}^{3}\right)$ across the mouse brain we visualized the $\mathrm{T}_{1}$ shortening in the OB and the LOT.

\section{Significantly lower dose of $\mathrm{MnCl}_{2}$ for MEMRI}

$\mathrm{Mn}^{2+}$ has proven to be useful in monitoring $\mathrm{Ca}^{2+}$ influx and measuring axonal transport rates in biological research (Serrano et al. 2008; Smith et al. 2007); however it is important to note that manganese is neurotoxic at high concentrations. Since the toxicity of manganese is associated with high concentrations, it is imperative to reduce the dose to avoid possible neurotoxicity, especially in longitudinal studies. In this study, we could lower the concentration of $\mathrm{MnCl}_{2}$ to 20 times lower ( $<5 \%$ of the dosages) than those used in previous studies (Serrano et al. 2008; Smith et al. 2007) with a sufficiently high contrast-to-noise ratio (CNR). By allowing $6 \mathrm{hr}$ of $\mathrm{Mn}^{2+}$ accumulation in the $\mathrm{OB}$ in conjunction with our $\mathrm{T}_{1}$ mapping method and high magnetic field, the detection sensitivity of MRI signal changes was greatly enhanced. Thus, we were able to obtain robust detection of MEMRI signal changes at this low total dose of $\mathrm{Mn}^{2+}$ and to quantify the axonal transport rates reliably. When animals were subjected to multiple MEMRI sessions, the axonal transport rates were consistent, and we did not observe any behavioral changes, suggesting no observable ill effects from $\mathrm{Mn}^{2+}$ at the current dose.

\section{Potential limitation of axonal transport measurement using MEMRI and future directions}

Since MEMRI measurements rely on $\mathrm{Mn}^{2+}$ accumulation and its concentration in the $\mathrm{OB}$, the axonal transport rate measured using MEMRI methods may include other contributing factors, such as uptake of $\mathrm{Mn}^{2+}$ in the olfactory sensory neurons in the turbinate, packaging of $\mathrm{Mn}^{2+}$ into the vesicles, and cargo binding to the motor protein, kinesin. In this study, we did not observe any difference in signal enhancement in the turbinate area between 3xTg$\mathrm{AD}$ and wt mice in all age groups demonstrating that uptake of $\mathrm{Mn}^{2+}$ in the olfactory sensory neurons is largely identical. However, MEMRI does not provide any information regarding packaging of $\mathrm{Mn}^{2+}$ and cargo binding. Therefore, the axonal transport indices measured using MEMRI should be interpreted as an index for overall axonal transport integrity rather than a simple rate of axonal cargo movement. Considering the fact that there are multiple targets for disturbing axonal transport in neurodegenerative diseases including $\mathrm{AD}$, axonal transport rate measurement using MEMRI in vivo can be used to assess overall integrity of axonal transport system that may be relevant to cognitive and behavioral outcomes.

The current findings of the axonal transport deficit could be correlated with biochemical and histochemical analysis results to associate with the presence of $\mathrm{A} \beta$ and tau pathology. Further study is needed to understand the mechanisms responsible for early axonal transport deficits in 3xTg-AD mice. In addition, the longitudinal axonal transport measurements should be possible by taking advantage of lower $\mathrm{MnCl}_{2}$ dosage and $\mathrm{T}_{1}$ mapping techniques to investigate the axonal transport deficits in disease progression and the effect of the drug treatment in the same cohorts of animals.

\section{Conclusion}

This study demonstrates that high resolution quantitative MEMRI is a valuable method for non-invasive measurements of axonal transport in the mouse brain. The combination of a novel quantitative $\mathrm{T}_{1}$ mapping MEMRI technique, a high sensitivity RF coil set and high magnetic field of $9.4 \mathrm{~T}$, provided a robust measurement of $\mathrm{R}_{1}$ changes in $\mathrm{OB}$ and other parts 
of the brain as well as a visualization of cellular layers of the OB structure with high signalto-noise ratio. Thus, this in vivo MEMRI approach should enable us to investigate axonal transport deficits in various transgenic mouse models of $\mathrm{AD}$ to evaluate the disease progression and the effect of drug treatments. This study also reports quantitative measurements of very early, yet subtle, axonal transport deficits in olfactory systems of $3 \times \mathrm{Tg}-\mathrm{AD}$ mice. Our data suggest that accumulation of intra-neuronal $\mathrm{A} \beta$ rather than the extra-cellular $A \beta$ or abnormal Tau may initially lead to the axonal transport impairment. However, further studies are needed to directly link intra-neuronal $A \beta$ and axonal transport deficits and to assess the effect of extracellular $A \beta$ and Tau pathology on axonal transport.

\section{Acknowledgments}

This study was supported in part by the Alzheimer's Association (NIRG-07-60405 to Dr. Lee), the National Institutes of Health (5R21AG027419 to Dr. Michaelis, C76 HF00201 and P30 HD002528) and the Hoglund Family Foundation. The Hoglund Brain Imaging Center is supported by a generous gift from Forrest and Sally Hoglund.

\section{References}

Billings LM, Oddo S, Green KN, McGaugh JL, LaFerla FM. Intraneuronal Abeta causes the onset of early Alzheimer's disease-related cognitive deficits in transgenic mice. Neuron. 2005; 45:675-688. [PubMed: 15748844]

Chuang K, Koretsky AP. Improved neuronal tract tracing using manganese enhanced magnetic resonance imaging with Fast T1 mapping. Magn Reson Med. 2006; 55:604-611. [PubMed: 16470592]

Cross DJ, Minoshima S, Anzai Y, Flexman JA, Keogh BP, Kim Y, Maravilla KR. Statistical mapping of functional olfactory connections of the rat brain in vivo. NeuroImage. 2004; 23:1326-1335. [PubMed: 15589097]

Cross DJ, Flexman JA, Anzai Y, Maravilla KR, Minoshima S. Age-related decrease in axonal transport measured by MR imaging in vivo. NeuroImage. 2008; 39:915-926. [PubMed: 17980625]

De Vos K, Grierson AJ, Ackerley S, Miller CCJ. Role of Axonal Transport in Neurodegenerative Diseases. Annu Rev Neurosci. 2008; 31:151-173. [PubMed: 18558852]

Gotz J, Ittner LM, Kins S. Do axonal defects in tau and amyloid precursor protein transgenic animals model axonopathy in Alzheimer's disease? J Neurochem. 2006; 98:993-1006. [PubMed: 16787410]

Hutton M, Lendon CL, Rizzu P, Baker M, Froelich S, Houlden H, Pickering-Brown S, Chakraverty S, Isaacs A, Grover A, Hackett J, Adamson J, Lincoln S, Dickson D, Davies P, Petersen RC, Stevens M, de Graaff E, Wauters E, van Baren J, Hillebrand M, Joosse M, Kwon JM, Nowotny P, Che LK, Norton J, Morris JC, Reed LA, Trojanowski J, Basun H, Lannfelt L, Neystat M, Fahn S, Dark F, Tannenberg T, Dodd PR, Hayward N, Kwok JB, Schofield PR, Andreadis A, Snowden J, Craufurd D, Neary D, Owen F, Oostra BA, Hardy J, Goate A, van Swieten J, Mann D, Lynch T, Heutink P. Association of missense 5'-splice-site mutations in tau with the inherited dementia FTDP-17. Nature. 1998; 393:702-705. [PubMed: 9641683]

Kim J, Choi I-Y, Michaelis ML, Lee S-P. Early impaired axonal transport in a triple transgenic mouse model of Alzheimer's disease. Proc Intl Soc Mag Reson Med. 2009; 18:540.

Lee S-P. Quantitative assessment of axonal transport integrity in the mouse brain in vivo using MEMRI at 9.4 T. Proc Intl Soc Mag Reson Med. 2007; 15:2441.

Look DC, Locker DR. Time saving in measurement of NMR and EPR relaxation times. Rev Sct Instrum. 1970; 41:250-251.

Morfini GA, Burns M, Binder LI, Kanaan NM, LaPointe N, Bosco DA, Brown RH, Brown H, Tiwari A, Hayward L, Edgar J, Nave K, Garberrn J, Atagi Y, Song Y, Pigino G, Brady ST. Axonal Transport Defects in Neurodegenerative Disease. J Neurosci. 2009; 29:12776-12786. [PubMed: 19828789]

Morfini GA, Burns M, Binder LI, Kanaan NM, LaPointe N, Bosco DA, Brown RH Jr, Brown H, Tiwari A, Hayward L, Edgar J, Nave KA, Garberrn J, Atagi Y, Song Y, Pigino G, Brady ST. Axonal transport defects in neurodegenerative diseases. J Neurosci. 2009; 29:12776-12786. [PubMed: 19828789] 
Oddo S, Caccamo A, Shepherd JD, Murphy MP, Golde E, Kayed R, Metherate R, Mattson MP, Akbari Y, LaFerla FM. Triple-Transgenic Model of Alzheimer's Disease with Plaques and Tangles: Intracellular Ab and Synaptic Dysfunction. Neuron. 2003; 39:409-421. [PubMed: 12895417]

Pan JW, Twieg DB, Hetherington HP. Quantitative Spectroscopic Imaging of the Human Brain. Magn Reson Med. 1998; 40:363-369. [PubMed: 9727938]

Pautler RG, Silva AC, Koretsky AP. In Vivo Neuronal Tract Tracing Using Manganese-Enhanced Magnetic Resonance Imaging. Magn Reson Med. 1998; 40:740-748. [PubMed: 9797158]

Pautler RG, Koretsky AP. Tracing Odod-Induced Activation in the Olfactory Bulbs of Mice Using Manganese-Enhanced Magnetic Resonance Imaging. NeuroImaging. 2002; 16:441-448.

Pautler RG. In vivo, trans-synaptic tract-tracing utilizing manganese-enhanced magnetic resonance imaging (MEMRI). NMR Biomed. 2004; 17:595-601. [PubMed: 15761948]

Pigino G, Morfini G, Atagi Y, Deshpande A, Yu C, Jungbauer L, LaDu M, Busciglio J, Brady S. Disruption of fast axonal transport is a pathogenic mechanism for intraneuronal amyloid beta. Proc Natl Acad Sci U S A. 2009; 106:5907-5912. [PubMed: 19321417]

Schindowski K, Belarbi K, Buee L. Neurotrophic factors in Alzheimer's disease: role of axonal transport. Genes Brain and Behav. 2007; 7:43-56.

Serrano F, Deshazer M, Smith KDB, Ananta JS, Wilson LJ, Pautler RG. Assessing Transneuronal Dysfunction Utilizing Manganese-Enhanced MRI (MEMRI). Magn Reson Med. 2008; 60:169_ 175. [PubMed: 18581360]

Smith KDB, Kallhoff V, Zheng H, Pautler RG. In vivo axonal transport rates decrease in a mouse model of Alzheimer's disease. NeuroImage. 2007; 35:1401-1408. [PubMed: 17369054]

Spillantini MG, Murrell JR, Goedert M, Farlow MR, Klug A, Ghetti B. Mutation in the tau gene in familial multiple system tauopathy with presenile dementia. Proc Natl Acad Sci U S A. 1998; 95:7737-7741. [PubMed: 9636220]

Stokin GB, Lillo C, Falzone TL, Brusch RG, Rockenstein E, Mount SL, Raman R, Davies P, Masliah E, Williams DS, Goldstein LS. Axonopathy and transport deficits early in the pathogenesis of Alzheimer's disease. Science. 2005; 307:1282-1288. [PubMed: 15731448]

Strupp JP. Stimulate: A GUI based fMRI Analysis Software Package. NeuroImage. 1996; 3:S607.

Wilson RJ. Towards a cure for dementia: the role of axonal transport in Alzheimer's disease. Sci Prog. 2008; 91:65-80. [PubMed: 18453283]

Wirths O, Weis J, Kayed R, Saido TC, Bayer TA. Age-dependent axonal degeneration in an Alzheimer mouse model. Neurobiol Aging. 2007; 28:1689-1699. [PubMed: 16963164] 


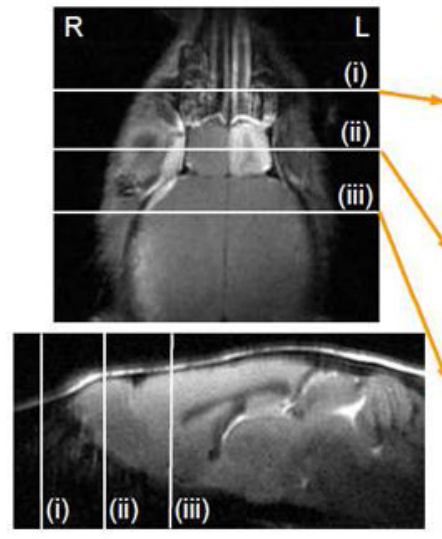

(A)

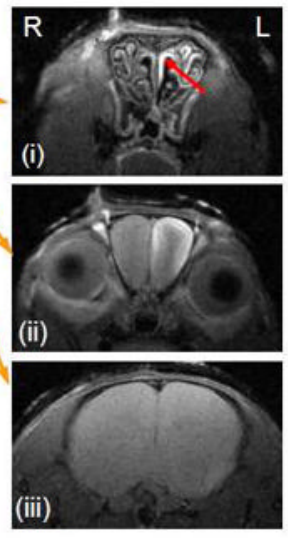

(B)

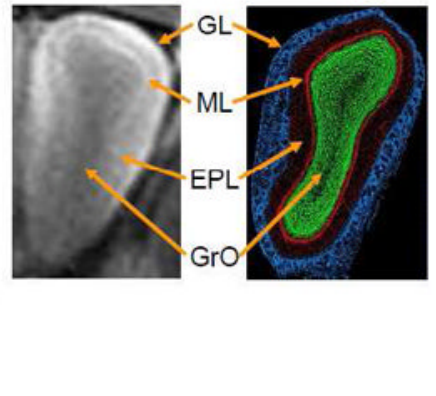

(C)

Figure 1. MEMRI of a 3xTg-AD mouse

(A) $\mathrm{T}_{1} \mathrm{w}$ high resolution coronal MEMRI (Top) and sagittal MRI (Bottom) of a 3xTg-AD mouse showing slice positions of MEMRI data acquisition: (i) turbinate; (ii) olfactory bulb (OB) and (iii) lateral olfactory tracks (LOT) at $6 \mathrm{~h}$ post $\mathrm{MnCl}_{2}$ administration. (B) Corresponding $\mathrm{T}_{1} \mathrm{w}$ high resolution $\left(78 \times 78 \times 450 \mu \mathrm{m}^{3}\right)$ transverse images of (i) the turbinate at $1 \mathrm{~h}$, (ii) the $\mathrm{OB}$ at $6 \mathrm{~h}$, and (iii) the LOT at $24 \mathrm{~h}$ post $\mathrm{MnCl}_{2}$ administration. (C) Extended view of the $\mathrm{OB}$ and a corresponding histological section of the $\mathrm{OB}$ illustrating the layered structure of the different cell types: the glomerular layer (GL); mitral cell layer (ML); external plexiform layer (EPL); and granule cell layer (GrO) [Image adapted from Wikipedia, public domain]. "R" in Fig. 1A and 1B indicates the animal's right and "L" indicates the animal's left. 

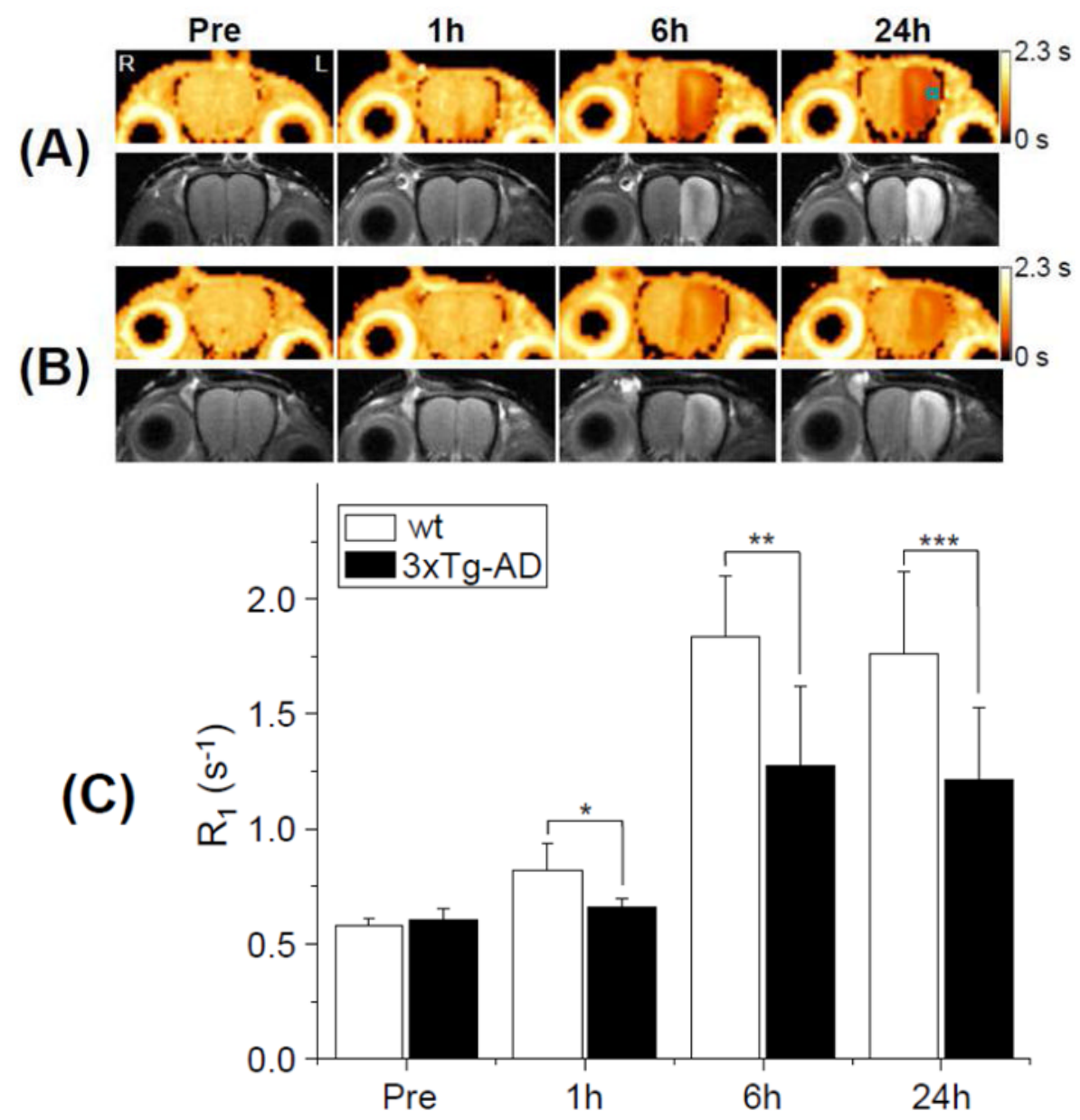

Figure 2. Quantification of the axonal transport rate

Two sets (A and $B$ ) of $T_{1}$ maps with corresponding $\mathrm{T}_{1} \mathrm{w}$ images of the $\mathrm{OB}$ of 3 mos old wt (A) and 3xTg-AD (B) mice at baseline, and $1 \mathrm{~h}, 6 \mathrm{~h}$, and $24 \mathrm{~h}$ post $\mathrm{MnCl}_{2}$ administration. The small square in the $\mathrm{T}_{1}$ map (top row right most) indicates the ROI inside of which the ATRI $\left(\left(\mathrm{R}_{1(6 \mathrm{~h})}-\mathrm{R}_{1(1 \mathrm{~h})}\right) / 5\right)$ of the OB was calculated. The gradient bars indicate the range of $\mathrm{T}_{1}$ values from $0 \mathrm{~s}$ to $2.3 \mathrm{~s}$. "R" in Fig. 2A (top row left most) indicates the animal's right and " $L$ " indicates the animal's left; this orientation holds for all figures displayed. (C) Longitudinal relaxation rate $\left(\mathrm{R}_{1}\right)$ at the $\mathrm{OB}$ of 3 mos old mice at baseline, and $1 \mathrm{~h}, 6 \mathrm{~h}$, and $24 \mathrm{~h}$ post $\mathrm{MnCl}_{2}$ administration, quantified from the ROI shown in Fig. $2 \mathrm{~A}$. ( $^{*}: \mathrm{p}=0.04$ for $1 \mathrm{~h} ; * *: \mathrm{p}=0.005$ for $6 \mathrm{~h} ; * * * \mathrm{p}=0.02$ for $24 \mathrm{~h} ; \mathrm{n}=8$ for $\mathrm{wt}$ and $\mathrm{n}=5$ for $3 \mathrm{xTg}-\mathrm{AD}$ ) 


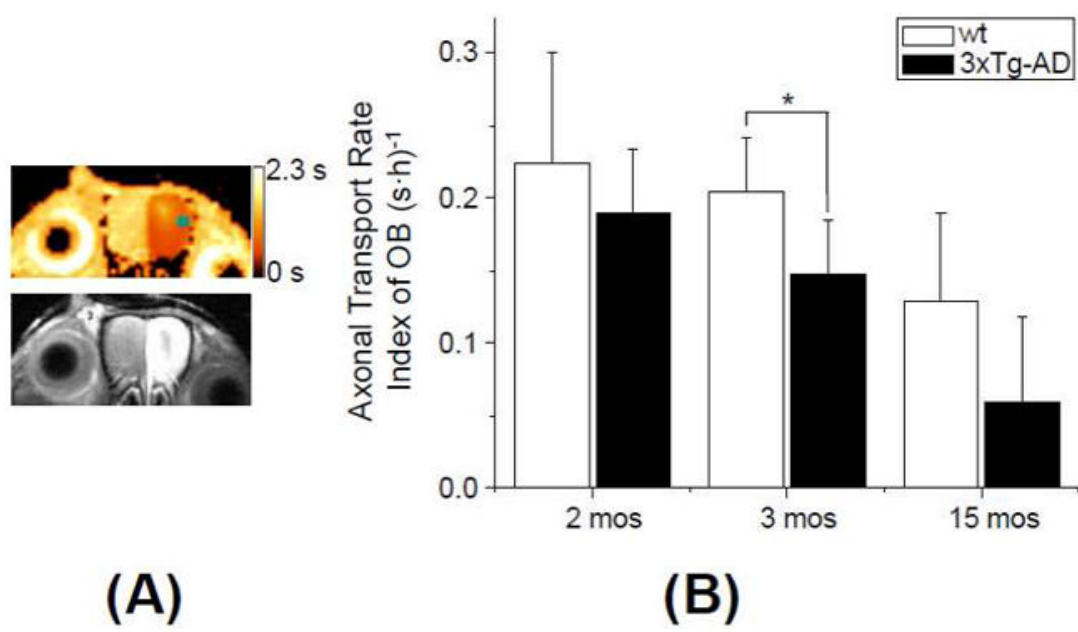

Figure 3. Axonal transport deficit in the OB

(A) $\mathrm{T}_{1}$ map with corresponding $\mathrm{T}_{1} \mathrm{w}$ MEMRI at the $\mathrm{OB}$ of a $3 \times \mathrm{Tg}$-AD mouse at 2 mos of age. MEMRI was performed at $6 \mathrm{~h}$ post $\mathrm{MnCl}_{2}$ administration. A small square in the upper panel shows an ROI where the ATRI in the OB $\left.\left(\mathrm{R}_{1(6 \mathrm{~h})}-\mathrm{R}_{1(1 \mathrm{~h})}\right) / 5\right)$ was obtained. The color scale bar indicates the range of $\mathrm{T}_{1}$ values of $0-2.3 \mathrm{~s}$. (B) Comparison of the ATRI in the OB between wt and $3 \times$ Tg-AD at $2 \operatorname{mos}(n=9$ for wt, $n=8$ for $3 x T g-A D), 3 \operatorname{mos}(n=8$ for wt, $n=4$ for $3 x T g-A D)$ and $15 \operatorname{mos}(n=5$ for wt, $n=6$ for $3 x T g-A D)$ of age at the OB. ( $\mathrm{p}=0.3$ for $2 \mathrm{mos} ; *$ : $\mathrm{p}=0.034$ for 3 mos; $\mathrm{p}=0.087$ for 15 mos of age) 


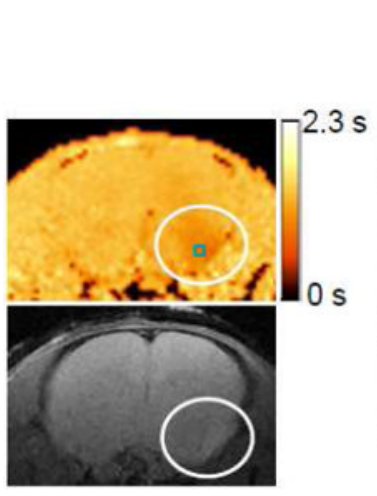

(A)

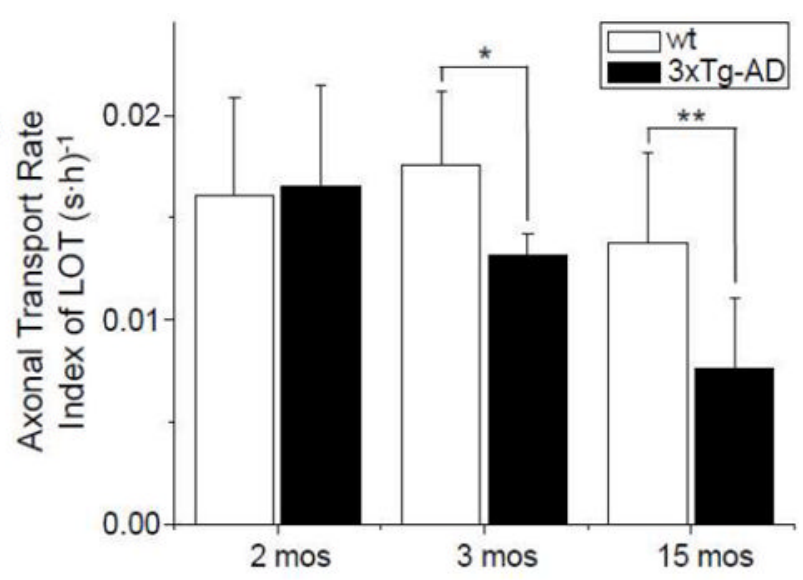

(B)

Figure 4. Axonal transport deficits in the LOT

(A) $\mathrm{T}_{1}$ map with corresponding $\mathrm{T}_{1} \mathrm{w}$ MEMRI at the LOT of a $3 \mathrm{xTg}-\mathrm{AD}$ mouse at 2 mos of age. MEMRI was performed at $24 \mathrm{~h}$ post $\mathrm{MnCl}_{2}$ administration. The circles indicate the LOT area with unilateral enhancement. A small square in the upper panel shows an ROI in which

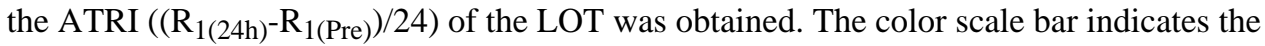
range of $\mathrm{T}_{1}$ values of $0-2.3 \mathrm{~s}$. (B) Comparison of the ATRI in the LOT between wt and $3 \times T g-A D$ at $2 \operatorname{mos}(n=9$ for wt and $n=8$ for $3 x T g-A D), 3$ mos $(n=8$ for wt and $n=5$ for $3 \times T g-A D)$ and $15 \operatorname{mos}(n=5$ for wt and $\mathrm{n}=6$ for $3 \times T g-A D)$. $(\mathrm{p}=0.88$ for 2 mos; $*: \mathrm{p}=$ 0.039 for 3 mos; $* *: p=0.028$ for 15 mos of age) 